\title{
Paroxysmal Sympathetic Hyperactivity in Patients Victims of Traumatic Brain Injury: Literature Review
}

\section{Hiperatividade simpática paroxística em pacientes vítimas de trauma cranioencefálico: Revisão da literatura}

\author{
Gabriela Ferreira Kalkmann ${ }^{1}$ Letícia Novak Crestani ${ }^{2}$ Letícia Adrielle dos Santos $^{3(1)}$ \\ Carlos Umberto Pereira4()
}

${ }^{1}$ Medical Faculty, Universidade Federal do Paraná, Curitiba, PR, Brazil
2 Medical Faculty, Faculdade de Medicina do Centro Universitário de
Maringá, Maringá, PR, Brazil
${ }^{3}$ Medical Faculty, Universidade Federal de Sergipe, Aracaju, SE, Brazil
${ }^{4}$ Neurosurgery Service, Hospital Urgência de Sergipe, Preceptor of
the Neurosurgery Residency at Surgery Hospital Charitable
Foundation, Aracaju, SE, Brazil

Address for correspondence Carlos Umberto Pereira, Av. Augusto Maynard, 245/404, São Jose, 49015-380 Aracaju - Sergipe, Brazil (e-mail: umberto@infonet.com.br).

Arq Bras Neurocir 2022;41:e70-e75.

\begin{abstract}
Keywords

- autonomic nervous system

- craniocerebral trauma

- primary dysautonomias

\section{Resumo}

Palavras-chave

- disautonomias primárias

- sistema nervoso autonômico

- trauma craniocerebral

The present literature review aims to present the physiology of paroxysmal sympathetic hyperactivity (PSH) as well as its clinical course, conceptualizing them, and establishing its diagnosis and treatment. Paroxysmal sympathetic hyperactivity is a rare syndrome, which often presents after an acute traumatic brain injury. Characterized by a hyperactivity of the sympathetic nervous system, when diagnosed in its pure form, its symptomatologic presentation is through tachycardia, tachypnea, hyperthermia, hypertension, dystonia, and sialorrhea. The treatment of PSH is basically pharmacological, using central nervous system suppressors; however, the nonmedication approach is closely associated with a reduction in external stimuli, such as visual and auditory stimuli. Mismanagement can lead to the development of serious cardiovascular and diencephalic complications, and the need for neurosurgeons and neurointensivists to know about PSH is evident in order to provide a fast and accurate treatment of this syndrome.

O presente artigo de revisão de literatura tem como objetivo apresentar a fisiologia da hiperatividade simpática paroxística (HPS), bem como sua evolução clínica, conceituando-as, estabelecendo seu diagnóstico e o tratamento. A HPS é uma síndrome rara, que geralmente se apresenta após uma lesão cerebral traumática aguda. A HPS é caracterizada por uma hiperatividade do sistema nervoso simpático, e quando diagnosticada na sua forma pura, apresenta sintomatologia através de taquicardia, taquipneia, hipertermia, hipertensão, distonia e sialorreia. O tratamento da HPS é basicamente farmacológico, por meio do uso de supressores do sistema nervoso
\end{abstract}

received

June 8,2020

accepted

February 22, 2021

published online

December 17, 2021
DOI https://doi.org/ $10.1055 / s-0041-1730370$ ISSN $0103-5355$.

\footnotetext{
(c) 2021. Sociedade Brasileira de Neurocirurgia. All rights reserved. This is an open access article published by Thieme under the terms of the Creative Commons Attribution-NonDerivative-NonCommercial-License, permitting copying and reproduction so long as the original work is given appropriate credit. Contents may not be used for commercial purposes, or adapted, remixed, transformed or built upon. (https://creativecommons.org/ licenses/by-nc-nd/4.0/)

Thieme Revinter Publicações Ltda., Rua do Matoso 170, Rio de Janeiro, RJ, CEP 20270-135, Brazil
} 
central, porém a abordagem não medicamentosa está intimamente associada à redução de estímulos externos, como visuais e auditivos. A má gestão pode levar ao desenvolvimento de complicações cardiovasculares e diencefálicas graves, e a necessidade de neurocirurgiões e neurointensivistas saberem sobre o HSP para fornecer um tratamento rápido e preciso dessa síndrome é evidente.

\section{Introduction}

The traumatic brain injury (TBI) is one of the main causes of death and severe sequelae. ${ }^{1}$ Severe TBI is characterized by a Glasgow Coma Scale (GCS) score between 3 and 8, which may require a long hospital stay, being a cause of prolonged disability. ${ }^{2,3}$ Often, after suffering a severe TBI, ${ }^{4}$ the patient can develop paroxysmal sympathetic hyperactivity (PSH), which is an uncommon complication ${ }^{5}$ that can occur in the first 24 hours ${ }^{6}$ or months after the trauma, ${ }^{2}$ with incidence of between 8 and $33 \%{ }^{7}$ in patients admitted with TBI in the intensive care unit (ICU), ${ }^{1}$ being frequent in young adult patients. ${ }^{8}$ In $10 \%$ of the cases of HSP in children, it occurs due to TBI, in association with a prolonged rehabilitation. ${ }^{7}$

Paroxysmal sympathetic hyperactivity was first described by Penfield in 1929 with the nomenclature of "autonomic diencephalic crisis"9 , being characterized by a hyperadrenergic syndrome, which occurs following an acute brain injury ${ }^{10}$ in response to a non-nociceptive stimulus. ${ }^{11}$ Paroxysmal sympathetic hyperactivity is a severe and debilitating sequel $^{7}$ which develops less frequently after ischemic stroke $^{12}(5 \%),{ }^{13}$ intra-aqueductal abscess, ${ }^{14}$ ischemic encephalopathy, ${ }^{15}$ cerebral hypoxia ${ }^{6}(10 \%),{ }^{16}$ hydrocephalus, ${ }^{11}$ autoimmune encephalitis, ${ }^{4}$ fatty cerebral embolism, ${ }^{17}$ agenesis of the corpus callosum, ${ }^{18}$ central nervous system (CNS) infection, hypoglycemia, and complications related to neoplastic lesions. ${ }^{19}$ Often, it occurs after the interruption of the administration of sedatives and narcotics in the ICU, ${ }^{6}$ contributing significantly to the mortality of these individuals, ${ }^{20}$ being associated with a worse neuropsychological outcome, ${ }^{2}$ and is expected prospectively when the patient presents poor outcomes after TBI, such as a long stay in the ICU, low GCS score, increased frequency of infections during hospitalization, need for tracheostomy, and long period of posttraumatic amnesia. $^{7}$

Paroxysmal sympathetic hyperactivity is characterized by an excess of catecholamines, ${ }^{2}$ arterial hypertension, ${ }^{5}$ transient paroxysmal fever, ${ }^{15}$ sweating, ${ }^{19}$ tachycardia, ${ }^{1}$ manifesting itself motorly through abnormal body posture associated with muscle spasticity ${ }^{15}$ related to decerebrate and decorticate movements; ${ }^{9}$ in an uncommon way, patients present pupillary dilation, ${ }^{6}$ high eye pressure, ${ }^{21}$ agitation ${ }^{4}$ and sialorrhea. ${ }^{18}$ These symptoms may have a duration of minutes or hours, and may occur multiple times in the same day. ${ }^{22}$ The syndrome is classified as pure PSH when there is only discharge of sympathetic activity, and mixed in situations that evolve in association with sympathetic and parasympathetic hyperactivities. ${ }^{13,19}$ The latter appears through bradypnea, bradycardia, arterial hypotension, hypothermia, and miotic pupils. ${ }^{18}$

Since PSH is a rare syndrome associated with poor postTBI outcomes and it is difficult to diagnose, the present study aims to present its pathophysiology and symptoms, conceptualizing them, thus advocating its diagnosis and treatment.

\section{Materials and Methods}

The present paper is a literature review using the following databases: PubMed, Scielo, Scientific Direct, Ebsco, LILACS, Trip DataBase and Cochrane, using the terms: Paroxysmal Sympathetic Hyperactivity. Articles from 2004 to 2019 were selected, resulting in a total of 33 articles that met the inclusion criteria considering their citations and respective impacts.

\section{Results}

\section{Physiopathology}

The primary formation sites of the autonomic response in the CNS are the spinal cord, the brainstem, and the hypothalamus. ${ }^{12}$ The autonomic nervous system (ANS) performs cardiac and vascular control through the regulation of exocrine and endocrine glands and of cardiac and smooth muscles, influencing the modulation of tissues and organs of different systems. ${ }^{21}$ There is no postulated pathophysiology for HSP, but the following theories are the most accepted: due to the overlap of the sympathetic nervous system over the parasympathetic, ${ }^{6}$ which may be associated with brainstem damage due to TBI or neoplasia ${ }^{19}$; axonal shear injury and consequent disinhibition of subcortical sympathetic excitatory structures ${ }^{8}$; injury that occurs from the limbic cortex to the sympathetic centers, which can remove the tonic inhibition from the insular cortex, developing an uncontrollable sympathetic storm ${ }^{10}$; and lesions involving the splenium or the corpus callosum and the right posterior branch of the internal capsule. $^{12}$

The dysregulation of the heart rhythm occurs due to the general cardiovascular decrease at rest due to the sympathetic system 19 and vagal activity by the ANS in the sinus node of the heart. ${ }^{21}$ During PSH, there may be a decrease in the sensitivity of the baroreflex complex, which is closely linked to cardiovascular complications and to an increase in the occurrence of arterial hypertension. ${ }^{21}$ The increase in catecholamines causes high rates of epinephrine and norepinephrine identified in the blood plasma; these neurotransmitters can lead to the development of a persistent comatose state. $^{2}$ 
Decerebrate and decorticate postures can be explained by lesions located in the anterior hypothalamus, the midbrain, the centers of the cerebral cortex (orbitofrontal, anterior temporal and insula) and in subcortical areas (amygdala, periaqueductal gray substance, solitary tract nucleus and cerebellar worms). ${ }^{18}$ The thermal deregulation present in PSH occurs due to the involvement of the hypothalamus or through the hypermetabolic state associated with muscle contractions. $^{22}$

\section{Clinical Course}

After the brain injury, the symptomatic presentation of PSH occurs in between 1 and 60 days, and should be monitored during the first weeks. ${ }^{7}$ It manifests itself by increasing the activity of the sympathetic and motor nervous system in response to a typically benign stimulus, which normally does not trigger an intense physiological response. ${ }^{11}$ It has three phases: the first begins on admission at the ICU, ending with the cessation of paralysis or sedation ${ }^{14}$; the second occurs with the end of regular sedation, and ends with the extinction of regular PSH episodes. ${ }^{17}$ At the beginning of this phase, episodes are frequent, prolonged and intense. ${ }^{14}$ Some episodes may occur due to a detectable agent such as pain, exposure to light, and passive movement such as bathing, ${ }^{17}$ changing the decubitus position, muscle stretching, endotracheal suction, constipation, twisted urinary catheter, and emotional and environmental stimuli, such as loud sound. Finally, the third phase begins, with the end of regular episodes, although patients with severe PSH may present with sequelae, such as joint deformities and reduced range of motion. $^{14}$

The most common symptoms of PSH are hyperthermia ${ }^{23}$; excessive diaphoresis ${ }^{12}$; posture in extension, ${ }^{3}$ decerebrate, decortication, rigidity and spasticity ${ }^{14}$; dystonia; tachycar$\mathrm{dia}^{7}$; excessive salivation; tachypnea; and arterial hypertension. ${ }^{24}$ These signs and symptoms vary from episode to episode, as well as from individual to individual. ${ }^{6}$ The interruption of diaphoresis is used as a mark between the second and third phases, frequently occurring on the $74^{\text {th }}$ day after the brain injury. ${ }^{9}$ When an episode of mixed PSH occurs, the symptoms manifested are miosis, tearing, bradycardia, bradypnea, hypotension, hypothermia, tidal breathing, and yawning. ${ }^{25}$

\section{Diagnosis}

The diagnosis is established on an exclusion basis, deciding on other possible diagnoses, and requires a wide degree of suspicion. ${ }^{17}$ It is performed through anamnesis and detailed physical examination, associated with continuous monitoring of heart rate, electrocardiogram, blood pressure, and temperature. ${ }^{23}$ Imaging tests such as computed tomography (CT) and magnetic resonance imaging (MRI) are not necessary for the diagnosis of PSH; however, they contribute to the confirmation of the diagnosis, showing the type of lesion (axonal or diffuse) and its morphology, such as ischemia and cerebral hemorrhage. ${ }^{17}$ As a diagnostic criterion for PSH, Baguley et al. $^{26}$ developed a combined scale, through the association of a score of presence and clinical severity, the
Severity of Clinical Characteristics Scale, and the score of characteristics of PSH episodes ( $\boldsymbol{- T a b l e} \mathbf{1}$ ). The final score is used for the diagnostic calculation of PSH.

For the diagnosis of exclusion for infections, routine hematological and biochemical tests, such as blood, urine, tracheal aspirate, and sputum culture should be performed. ${ }^{23}$ And the diagnostic test based on the administration of intravenous morphine sulfate should be performed to check the control of dysautonomias; ${ }^{18}$ if the result is positive, the patient is diagnosed with PSH.

\section{Treatment}

The treatment of PSH is pharmacological, nonpharmacological, and the prevention of specific sympathetic symptoms. ${ }^{11}$ Drugs that depress the CNS, with consequent suppression of the ANS, are often used, ${ }^{6}$ such as opioid agonists, nonselective $\beta$-blockers, ${ }^{8}$ dopaminergic agonists, $\alpha$-blockers, sedatives, ${ }^{6}$ and $\alpha$ agonists. ${ }^{23}$ Therefore, drugs such as bromocriptine, clonidine, dantrolene, ${ }^{27}$ intrathecal baclofen, ${ }^{23}$ gabapentin, and benzodiazepines ${ }^{7}$ are widely used. This last group presents good results in the symptomatic treatment of $\mathrm{PSH}^{4}{ }^{4}$ and $\beta$ blockers decrease the synthesis of catecholamines, ${ }^{18}$ and are administered due to their lipophilic characteristic, and because they easily cross the blood-brain barrier. ${ }^{16}$ In the ICU, intravenous drugs such as morphine, fentanyl and midazolam are the first line of treatment. ${ }^{6}$ Morphine, an opioid agonist, performs analgesia and alters the extreme changes of the ANS, as well as dystonia by suppressing the sympathetic flow. ${ }^{9}$ Sedatives such as dexmedetomidine and propofol are used to manage episodes of PSH in the ICU. The first is an active $\alpha-2$ adrenergic agonist intravenous substance that can be administered through continuous infusion. ${ }^{16}$

The nonpharmacological treatment is based on thermal control of the environment, ${ }^{28}$ associated with body cooling through devices, such as blankets ${ }^{29}$; decrease in probable visual and auditory stimuli from the environment ${ }^{30}$; in association with body exercises and massages. ${ }^{29}$ The management of PSH rehabilitation aims to minimize the disabilities and complications that can be avoided, as well as to increase the chances of the patient recovering a good quality of life. ${ }^{14}$

\section{Complications}

When treated incorrectly, PSH leads to an increased risk of secondary brain injury. ${ }^{6}$ The high adrenergic activity of $\mathrm{PSH}^{4}$ in association with several episodes of the phenomenon can result in secondary morbidities such as elevated intracranial pressure, cardiac injury, metabolic disorders, ${ }^{19}$ systemic abnormalities throughout the body, and increased mortality. ${ }^{21} \mathrm{~A}$ hypermetabolic state during sympathetic hyperactivity can reduce body weight by $25 \%$ during just one episode. Lee et al. ${ }^{19}$ identified an increased concentrations of muscle enzymes after the occurrence of PSH. Hypernatremia may occur due to intense diaphoresis. ${ }^{6}$ Paroxysmal sympathetic hyperactivity leads to the evolution of cerebral vasoconstriction, which contributes to local edema and increased intracranial pressure. ${ }^{31}$ A cardiac sequela can 
Table 1 Paroxysmal Sympathetic Hyperactivity - Assessment Measure

\begin{tabular}{|c|c|c|c|c|c|}
\hline \multicolumn{6}{|l|}{ Clinical Feature Scale (CFS) } \\
\hline & 0 & 1 & 2 & 3 & Score \\
\hline Heart rate & $<100$ & $100-119$ & $120-139$ & $\geq 140$ & \\
\hline Respiratory rate & $<18$ & $18-23$ & $24-29$ & $\geq 30$ & \\
\hline Systolic blood pressure & $<140$ & $140-159$ & $160-179$ & $\geq 180$ & \\
\hline Temperature & $<37$ & $37-37.9$ & $38-38.9$ & $\geq 39$ & \\
\hline Sweating & Absence & Mild & Moderate & Severe & \\
\hline \multirow[t]{2}{*}{ Posturing during episodes } & Absence & Mild & Moderate & Severe & \\
\hline & & & & CFS Subtotal & \\
\hline \multirow[t]{4}{*}{ Severity of clinical features } & & & Absence & 0 & \\
\hline & & & Mild & $1-6$ & \\
\hline & & & Moderate & $7-12$ & \\
\hline & & & Severe & $\geq 13$ & \\
\hline \multicolumn{6}{|c|}{ Diagnosis Likelihood (DLT) - Score 1 point for each feature present } \\
\hline \multicolumn{6}{|c|}{ Clinical features occur simultaneously } \\
\hline \multicolumn{6}{|c|}{ Episodes are paroxysmal in nature } \\
\hline \multicolumn{6}{|c|}{ Sympathetic over-reactivity to normally non-painful stimuli } \\
\hline \multicolumn{6}{|c|}{ Features persist $\geq 3$ consecutive days } \\
\hline \multicolumn{6}{|c|}{ Features persist $\geq 2$ weeks post brain injury } \\
\hline \multicolumn{6}{|c|}{ Features persist despite treatment of alternative differential diagnoses } \\
\hline \multicolumn{6}{|c|}{ Medication administered to decrease sympathetic features } \\
\hline \multicolumn{6}{|l|}{$\geq 2$ episodes daily } \\
\hline \multicolumn{6}{|c|}{ Absence of parasympathetic features during episodes } \\
\hline \multicolumn{6}{|c|}{ Absence of other presumed cause of features } \\
\hline \multicolumn{6}{|l|}{ Previous acquired brain injury } \\
\hline & & & & Subtotal DLT & \\
\hline \multicolumn{6}{|l|}{ Combined Total (CFS + DLT) } \\
\hline \multirow[t]{3}{*}{ PSH diagnostic likelihood } & & & Unlikely & $<8$ & \\
\hline & & & Possible & $8-16$ & \\
\hline & & & Probable & $>17$ & \\
\hline
\end{tabular}

Baguley et $\mathrm{al}^{26}$

lead to the development of arrhythmias, of ischemia and of cardiac dysfunction, consequently reducing cerebral perfusion. ${ }^{21}$ The use of splints during episodes of PSH can lead to areas of pressure and tendon rupture, as well as to the lack of voluntary movement, and may cause the development of locked-in syndrome. ${ }^{14}$

\section{Discussion}

Paroxysmal sympathetic hyperactivity has numerous names, $\sim 31,{ }^{23}$ such as sympathetic discharge, ${ }^{6}$ diencephalic seizures, autonomic discharge, paroxysmal autonomic instability associated with dystonia, dysautonomia, ${ }^{4}$ paroxysmal sympathetic hyperactivity, ${ }^{3}$ and dysfunction of the autonomic nervous system. ${ }^{21}$ The name of diencephalic seizure for PSH is somewhat incorrect, because the result of the electroencephalogram is normal.,27 Paroxysmal sympathetic hyperactivity is used as a diagnosis of exclusion, but it can coexist with other complications, such as infections. $^{4}$ In 2014, an international consensus group defined PSH as "a syndrome in which an individual who has suffered an acute acquired brain injury develops increases in transient paroxysmal sympathetic activities, such as tachycardia, tachypnea, hypertension, hyperthermia, and diaphoresis, as well as motor manifestations, such as dystonia" 26 .

A differential diagnosis for PSH is serotonin syndrome, the latter developing strictly due to complications after pharmacological administration (fentanyl or tramadol), in which the excessive presence of postsympathetic serotonergic receptors occurs. Primarily, this drug complication affects the CNS, being characterized by changes in mental status, signs of neuromuscular irritation and autonomic instability, but it can manifest itself through increased muscle tone, 
diaphoresis, and fever, ${ }^{32}$ commonly present in PSH. Some syndromes can simulate PSH, such as neuroleptic malignant syndrome, malignant hyperthermia, pheochromocytoma, hyperthyroidism, sepsis, ${ }^{23}$ drug and alcohol withdrawal syndrome, acute myocardial infarction, and thromboembolic disease. ${ }^{17}$ Therefore, the diagnosis of PSH is made by confirming the intracranial lesion through imaging tests, ${ }^{17}$ as well as by routine laboratory tests for infectious, blood count, and biochemical conditions. ${ }^{23}$

The management of PSH is symptomatic, through its prevention in association with pharmacological administration, as well as nonpharmacological methods. ${ }^{11,28-30}$ In a study, Tang et al. ${ }^{33}$ demonstrated that the $\alpha$ agonist drug dexmedetomidine, a sedative used for patients recovering from TBI in the ICU, can be used to prevent PSH. The family of the patient can perceive the onset of an episode of PSH from the worsening of the mental state of the patient; with this, they can warn the clinical staff ${ }^{6}$ so that the management occurs as soon as possible to avoid the development of serious sequelae.

The importance of knowledge by neurosurgeons and neurointensivists about the diagnosis, treatment and prevention in an early and accurate way of the symptoms of PSH is evident to avoid the evolution of serious results.

\section{Conflict of Interests}

The authors have no conflict of interests to declare.

\section{References}

1 Kanjwal K, Karabin B, Kanjwal Y, Grubb BP. Autonomic dysfunction presenting as postural tachycardia syndrome following traumatic brain injury. Cardiol J 2010;17(05):482-487

2 Patel MB, McKenna JW, Alvarez JM, et al. Decreasing adrenergic or sympathetic hyperactivity after severe traumatic brain injury using propranolol and clonidine (DASH After TBI Study): study protocol for a randomized controlled trial. Trials 2012; 13:177

3 Godbolt AK, Stenberg M, Jakobsson J, et al. Subacute complications during recovery from severe traumatic brain injury: frequency and associations with outcome. BMJ Open 2015;5(04): e007208

4 Hughes JD, Rabinstein AA. Early diagnosis of paroxysmal sympathetic hyperactivity in the ICU. Neurocrit Care 2014;20(03): 454-459

5 Inoue A, Ebina M, Atsumi T, Ariyoshi K. Refractory paroxysmal sympathetic hyperactivity following brain injury in a pregnant woman that dramatically improved after delivery. Acute Med Surg 2015;3(03):268-271

6 Lemke DM. Sympathetic storming after severe traumatic brain injury. Crit Care Nurse 2007;27(01):30-37, quiz 38

7 Kirk KA, Shoykhet M, Jeong JH, et al. Dysautonomia after pediatric brain injury. Dev Med Child Neurol 2012;54(08):759-764

8 Bower RS, Sunnarborg R, Rabinstein AA, Wijdicks EFM. Paroxysmal sympathetic hyperactivity after traumatic brain injury. Neurocrit Care 2010;13(02):233-234

9 Magalhães FN, Paiva WS, Andrade AF, et al. Considerações sobre a síndrome da disfunção autonômica pós traumatismo cranioencefálico: fisiopatologia e tratamento. Braz Neurosurg 2012;31 (02):75-80

10 Gao B, Pollock JA, Hinson HE. Paroxysmal sympathetic hyperactivity in hemispheric intraparenchymal hemorrhage. Ann Clin Transl Neurol 2014;1(03):215-219
11 Compton E. Paroxysmal sympathetic hyperactivity syndrome following traumatic brain injury. Nurs Clin North Am 2018;53 (03):459-467

12 Hinson HE, Puybasset L, Weiss N, et al; Neuro Imaging for Coma Emergence, Recovery (NICER) Consortium. Neuroanatomical basis of paroxysmal sympathetic hyperactivity: a diffusion tensor imaging analysis. Brain Inj 2015;29(04):455-461

13 Meyfroidt G, Baguley IJ, Menon DK. Paroxysmal sympathetic hyperactivity: the storm after acute brain injury. Lancet Neurol 2017;16(09):721-729

14 Perkes IE, Baguley IJ. Current understanding of dysautonomia after severe acquired brain injury. ACNR 2008;8(01):10-11

15 Godo S, Irino S, Nakagawa A, et al. Diagnosis and management of patients with paroxysmal sympathetic hyperactivity following acute brain injuries using a consensus-based diagnostic tool: A single institutional case series. Tohoku J Exp Med 2017;243(01): $11-18$

16 Thomas A, Greenwald BD. Paroxysmal sympathetic hyperactivity and clinical considerations for patients with acquired brain injuries: A narrative review. Am J Phys Med Rehabil 2019;98 (01):65-72

17 Godoy DA, Panhke P, Guerrero Suarez PD, Murillo-Cabezas F. Paroxysmal sympathetic hyperactivity: An entity to keep in mind. Med Intensiva 2019;43(01):35-43

18 Domínguez-Jiménez E, Piña-Ramírez BM, García-Ramírez JL, et al. Hiperactividad simpática paroxística: Descripción de dos casos pediátricos y revisión de la literatura. Revista Mexicana de Neurosciencia. 2012;13(02):98-103

19 Lee S, Jun GW, Jeon SB, Kim CJ, Kim JH. Paroxysmal sympathetic hyperactivity in brainstem-compressing huge benign tumors: clinical experiences and literature review. Springerplus 2016; 5:340

20 Hilz MJ, Wang R, Markus J, et al. Severity of traumatic brain injury correlates with long-term cardiovascular autonomic dysfunction. J Neurol 2017;264(09):1956-1967

21 Esterov D, Greenwald BD. Autonomic Dysfunction after mild traumatic brain injury. Brain Sci 2017;7(08):100

22 Blackman JA, Patrick PD, Buck ML, Rust RS Jr. Paroxysmal autonomic instability with dystonia after brain injury. Arch Neurol 2004;61(03):321-328

23 Verma R, Giri P, Rizvi I. Paroxysmal sympathetic hyperactivity in neurological critical care. Indian J Crit Care Med 2015;19(01): 34-37

24 Fernández-Ortega JF, Prieto-Palomino MA, Muñoz-Lopez A, Hernández-Sierra B, Séller-Pérez G, Quesada-García G. Crisis disautonómicas tras traumatismo craneoencefálico grave. Med Intensiva 2004;28(07):376-379

25 Peng Y, Zhu H, Chen H, et al. Dexmedetomidine attenuates acute paroxysmal sympathetic hyperactivity. Oncotarget 2017;8(40): 69012-69019

26 Baguley IJ, Perkes IE, Fernandez-Ortega JF, Rabinstein AA, Dolce G, Hendricks HTConsensus Working Group. Paroxysmal sympathetic hyperactivity after acquired brain injury: consensus on conceptual definition, nomenclature, and diagnostic criteria. J Neurotrauma 2014;31(17):1515-1520

27 Ghatala MZ, Murugan S, Mahadevan S, Booma S. A rare case of diencephalic seizures secondary to hemorrhagic stroke. India Journal of Clinical Practice. 2014;24(11):1043-1045

28 Totikov A, Boltzmann M, Schmidt SB, Rollnik JD. Influence of paroxysmal sympathetic hyperactivity (PSH) on the functional outcome of neurological early rehabilitation patients: a case control study. BMC Neurol 2019;19(01):162

29 Burton JM, Morozova OM. Calming the storm: Dysautonomia for the pediatrician. Curr Probl Pediatr Adolesc Health Care 2017;47 (07):145-150

30 Letzkus L, Keim-Malpass J, Anderson J, Kennedy C. Paroxysmal sympathetic hyperactivity in children: An exploratory evaluation of nursing interventions. J Pediatr Nurs 2017;34:e17-e21 
Paroxysmal Sympathetic Hyperactivity in Patients Victims of Traumatic Brain Injury Kalkmann et al. 75

31 Ahl R, Thelin EP, Sjölin G, et al. $\beta$-Blocker after severe traumatic brain injury is associated with better long-term functional outcome: a matched case control study. Eur J Trauma Emerg Surg 2017;43(06):783-789

32 Pedavally S, Fugate JE, Rabinstein AA. Serotonin syndrome in the intensive care unit: clinical presentations and pre- cipitating medications. Neurocrit Care 2014;21(01): 108-113

33 Tang $\mathrm{Q}, \mathrm{Wu} \mathrm{X}$, Weng $\mathrm{W}$, et al. The preventive effect of dexmedetomidine on paroxysmal sympathetic hyperactivity in severe traumatic brain injury patients who have undergone surgery: a retrospective study. PeerJ 2017;5:e2986 